\title{
Mindfulness in informal caregivers of palliative patients
}

\author{
MONIKA KÖGLER, MA, ${ }^{1}$ MONIKA BRANDSTÄTTER, MA, ${ }^{1}$ \\ GIAN DOMENICO BORASIO, MD, ${ }^{2}$ VERONIKA FENSTERER, MSC, ${ }^{3}$ \\ HELMUT KÜCHENHOFF, PHD, ${ }^{3}$ AND MARTIN JOHANNES FEGG, PHD ${ }^{1}$ \\ ${ }^{1}$ Interdisciplinary Center for Palliative Medicine, Ludwig-Maximilians-University, Munich, Germany \\ ${ }^{2}$ Centre Hospitalier Universitaire Vaudois, Service de Soins Palliatifs, University of Lausanne, Lausanne, Switzerland \\ ${ }^{3}$ Statistical Consulting Unit, Department of Statistics, Ludwig-Maximilians-University, Munich, Germany \\ (Received February 17, 2013; AccePted March 22, 2013)
}

\begin{abstract}
Objectives: Mindfulness is a concept of growing impact on psychotherapy and has been shown to be effective for stress reduction and to improve psychological well-being. Existential

Behavioural Therapy (EBT) was developed to support relatives of palliative care (PC) patients to cope with their situation during caregiving and bereavement. Mindfulness training was a core element of the intervention. We investigated the relationship between mindfulness, mental distress, and psychological well-being in informal caregivers, and evaluated if the effects of the intervention were mediated by mindfulness.

Methods: Relatives of PC inpatients took part in a randomized-controlled EBT trial and completed the Cognitive and Affective Mindfulness Scale-Revised, items from the Five Facets of Mindfulness as well as the Brief Symptom Inventory, the Satisfaction with Life Scale, the WHOQOL-BREF, a numerical rating scale on quality of life (range 0-10), and the Schedule for Meaning in Life Evaluation at pre- and post-intervention, and a 3- and 12-months follow-up.

Results: One-hundred-and-thirty carers were included, most of them (71.6\%) recently being bereaved at the beginning of the intervention. High correlations between mindfulness and mental distress $(r=-0.51, p<0.001)$ as well as life satisfaction $(r=0.52, p<0.001)$ were found. Mindfulness was a significant predictor of improvement in psychological distress, meaning in life and quality of life three months after the intervention. The EBT effects were partly mediated by mindfulness.

Significance of results: Mindfulness seems to be a promising concept in supporting informal caregivers of PC patients. Further research is needed to identify the required format and intensity of mindfulness practice necessary for improvement.
\end{abstract}

KEYWORDS: Relatives, Palliative care, Mindfulness, Meditation, Psychotherapy

\section{INTRODUCTION}

Relatives of palliative care (PC) patients are highly burdened during caregiving and bereavement (Kissane et al., 2003). Studies indicate that 30-50\% suffer from depression, anxiety, or adjustment disorders, especially during the first months after

Address correspondence and reprint requests to: Martin Fegg, Marchioninistr. 15, 81377 Munich, Germany. E-mail: martin@ fegg.de the loss of the patient (Chentsova-Dutton et al., 2002).

Mindfulness, a concept of growing impact in psychotherapy, has been shown to be effective for stress reduction and to help in coping with painful emotions (Kabat-Zinn, 2003). Originally, it is a Buddhist concept and has been described as "the awareness that emerges through paying attention on purpose, in the present moment, and non-judgmentally to the unfolding of experience moment by moment" (Kabat-Zinn, 2003). However, there is no consensus on a definition yet. A common distinction is between 
formal practice, particularly meditation, and informal mindful activity, i.e., present-centered awareness in daily routine. Dispositional mindfulness, a general tendency to be mindful in daily life, has been reported to correlate with mental health and well-being (Brown \& Ryan, 2003; Feldman et al., 2007).

Several mindfulness-based interventions have been designed to use "the benefits of being present" (Brown \& Ryan, 2003): Mindfulness Based Stress Reduction (MBSR) (Kabat-Zinn, 2003) has been applied to several conditions and settings (e.g., chronic pain, cancer patients, health care professionals). Mindfulness Based Cognitive Therapy was designed to prevent relapse in recurrent depression (Teasdale et al., 2000). Mindfulness techniques are also taught in combination with behavioral training (Hayes et al., 2006; Robins \& Chapman, 2004).

Meta-analyses and systematic reviews report significant effects of these interventions (Baer, 2003; Grossman et al., 2004; Nyklicek et al., 2010). However, the small number of randomized controlled studies and methodological problems have been criticized (Toneatto \& Nguyen, 2007). Currently, the research focuses on the necessary format and intensity of mindfulness training (Carmody \& Baer, 2009).

Decentering, the ability to step back from thoughts and feelings and observe them non-judgmentally without identification, has been discussed as a potential mediator of the benefits of mindfulness-based interventions (Shapiro et al., 2006). It has been described as particularly helpful during the grieving process because it helps to "ride the waves of grief" (Kumar, 2005), while not being overwhelmed by them. So far, only theoretical papers and exploratory studies deal with mindfulness in caregivers (Waelde et al., 2004) or during bereavement (Kang \& Yoo, 2007).

Existential Behavioural Therapy (EBT) has been developed to support informal caregivers facing the imminent or recent loss of a family member in a PC setting. Short- and long-term effects of this intervention on quality of life (QoL) and psychological distress have been found up to 12 months after treatment (Fegg et al., 2013). Mindfulness training was a core element of the intervention.

\section{AIMS}

The aims of this study were (1) to assess if dispositional mindfulness is related to mental distress and psychological well-being in informal caregivers of PC patients, (2) to evaluate whether the effect of the EBT intervention in this population was mediated by mindfulness, and (3) to explore the impact of formal and informal practice on interventional effects.

\section{METHODS}

The effects of mindfulness were studied in a randomized controlled trial (with equal randomization 1:1) evaluating EBT in comparison to a treatment-asusual control group in informal caregivers of PC patients (Fegg et al., 2013). Inclusion criteria were: (1) relative of a PC patient (life expectancy $\leq 6$ months), (2) at least 21 years old, (3) without severe psychiatric disease or significant cognitive impairment, and (4) sufficient knowledge of German. Informed consent was obtained from all participants. The study was approved by the Research Ethics Committee of the Munich University Hospital.

The EBT groups (six sessions, maximum of 10 participants/group, 22 hours in total) were led by trained psychotherapists (Fegg et al., 2013). Information on mindfulness was given during the first meetings. Every session included formal mindfulness practice (e.g., following one's breath while noticing and letting go of all thoughts, feelings and sensations) for at least 15 minutes. Participants received $\mathrm{CD}$ recordings with mindfulness exercises and were encouraged to practice at home at least twice a day for a minimum of 10 minutes. Furthermore, informal mindfulness (i.e., performing daily activities mindfully, e.g., brushing teeth, preparing meals) was practiced.

\section{MEASURES}

Self-report questionnaires were completed before (T1) and after intervention (T2, approx. 6 weeks after T1), and at follow-ups three (T3) and 12 (T4) months after the end of the intervention.

Mindfulness was assessed with the Cognitive and Affective Mindfulness Scale-Revised (CAMS-R) consisting of 12 items in the categories "Attention," "Present-focus," "Awareness," and "Acceptance" (Feldman et al., 2007). Furthermore, items were taken from the Five Facets of Mindfulness (Baer et al., 2006): the three items with the highest loadings on each of the five factors ("Non-reactivity to inner experience," "Observing," "Acting with awareness," "Describing," "Non-judging experience") were included. Psychological distress was assessed with the Brief Symptom Inventory (BSI, subscales depression, anxiety, somatization; and the global severity index, GSI) (Franke, 2000). Raw scores were converted into gender-adjusted $T$-values. QoL was assessed with the WHOQOL-Bref (26 Items, total score range 0-100) (Angermeyer et al., 2000). A numerical rating scale on overall QoL (QoL-NRS, range 
$0-10)$ as well as the Satisfaction with Life Scale (SWLS, five items, range 1 to 7) have been included (Diener et al., 1985). Meaning in life was assessed with the Schedule for Meaning in Life Evaluation (SMiLE) (Fegg et al., 2008).

\section{STATISTICAL ANALYSES}

The analyses were carried out using SPSS (v19). The (two-sided) significance level was $p=0.05$. Due to the exploratory character of the study, no Bonferroni correction was performed.

Partial, age- and gender-adjusted Pearson correlations were calculated between mindfulness, psychological distress and QoL. To examine the impact of dispositional mindfulness (measured at T1) on psychological distress, QoL and meaning in life (measured at T2, T3, and T4) regression analyses (adjusted for the respective pre-treatment values) were performed (Vickers \& Altman, 2001). We controlled for age (metric), gender, relation to the patient (partner/child vs. parent/other), time of death $(\geq 6$ weeks before vs. $<6$ weeks before/during vs. after intervention), use of other psychosocial support (yes/ no), and group participation (yes/no). To test the mediation effect, $\Delta$ mindfulness (difference between T1 and T2/T3/T4) was additionally included. Only for the EBT group, the effect of mindfulness training was investigated by including frequencies of formal/informal practice (dichotomous, split at 75\%quartile; adjusted for the respective pre-treatment values of the outcomes) as co-variables into the linear models. Conditional normality of the outcome variables was checked using the respective model residuals. The regression coefficient ( $B$-value) and its 95\% confidence interval (CI) are reported.

\section{RESULTS}

\section{Sample}

One-hundred-and-sixty informal caregivers took part in the trial; mindfulness data were available for 130 participants. Missing data were due to early dropouts $(n=19)$ and questionnaires with missing mindfulness scales $(n=11)$. Ten EBT groups consisting of averagely $7.3 \pm 1.1$ participants were successfully carried out between 06/2008-06/2010. Table 1 shows socio-demographic characteristics of the study participants.

\section{Effects of Dispositional Mindfulness}

Table 2 shows mindfulness scores at T1. Table 3 summarizes correlations between mindfulness, mental health, and psychological well-being at T1. We controlled for age and gender, because these variables influenced mindfulness: the older the participants, the higher was their mindfulness (CAMS-R, $r=$ $0.32, p<0.02)$. Men $(2.8 \pm 0.5)$ had higher scores in comparison to women $(2.6 \pm 0.4 ; t=-3.23, p=$ 0.002).

Except for "Observing," correlations were moderate to large. In exploratory analyses, similar

Table 1. Sample characteristics

\begin{tabular}{|c|c|c|c|}
\hline & Intervention $(n=73)$ & Control $(n=57)$ & Total Sample $(n=130)$ \\
\hline Age (in years): $\mathrm{M} \pm \mathrm{SD}$ & $54.5 \pm 13.6$ & $54.0 \pm 13.2$ & $54.3 \pm 13.4$ \\
\hline Gender, women: \% & $72.6 \%$ & $68.4 \%$ & $70.8 \%$ \\
\hline \multicolumn{4}{|l|}{ Patient is: \% } \\
\hline Partner & $58.9 \%$ & $64.9 \%$ & $61.5 \%$ \\
\hline Parent & $26.0 \%$ & $28.1 \%$ & $26.9 \%$ \\
\hline Child & $2.7 \%$ & $3.5 \%$ & $3.1 \%$ \\
\hline Other & $12.3 \%$ & $3.5 \%$ & $8.5 \%$ \\
\hline \multicolumn{4}{|l|}{ Level of Education: \% } \\
\hline None or secondary & $24.7 \%$ & $15.8 \%$ & $20.8 \%$ \\
\hline Vocational secondary/grammar school & $45.2 \%$ & $42.1 \%$ & $43.8 \%$ \\
\hline University degree & $24.7 \%$ & $40.4 \%$ & $31.5 \%$ \\
\hline Other/missing & $5.5 \%$ & $1.8 \%$ & $3.8 \%$ \\
\hline \multicolumn{4}{|l|}{ Patient deceased: $\%$} \\
\hline$\geq 6$ weeks before $\mathrm{T} 1$ & $38.4 \%$ & $54.4 \%$ & $45.4 \%$ \\
\hline$<6$ weeks before $\mathrm{T} 1$ to $\mathrm{T} 2$ & $41.1 \%$ & $22.8 \%$ & $33.1 \%$ \\
\hline After T2 & $20.5 \%$ & $22.8 \%$ & $21.5 \%$ \\
\hline Use of other psychosocial support: \% & $28.8 \%$ & $21.1 \%$ & $25.4 \%$ \\
\hline \multicolumn{4}{|l|}{ Diagnosis of Patient: \% } \\
\hline Cancer & $80.8 \%$ & $80.7 \%$ & $80.8 \%$ \\
\hline Neurological & $12.3 \%$ & $15.8 \%$ & $13.8 \%$ \\
\hline Other & $6.9 \%$ & $3.5 \%$ & $5.4 \%$ \\
\hline
\end{tabular}


Table 2. Mindfulness at T1

\begin{tabular}{|c|c|c|c|c|c|c|}
\hline Outcome & EBT/Control & $n$ & $\mathrm{M} \pm \mathrm{SD}$ & $\mathrm{T}$ & $\mathrm{df}$ & $p$ \\
\hline \multirow[t]{2}{*}{ CAMS-R } & $\mathrm{EBT}$ & 57 & $2.69 \pm 0.41$ & 1.05 & 128 & $\mathrm{~ns}$ \\
\hline & Control & 73 & $2.60 \pm 0.50$ & & & \\
\hline \multirow[t]{2}{*}{ Act Aware } & EBT & 56 & $2.33 \pm 0.63$ & -0.22 & 126 & $\mathrm{~ns}$ \\
\hline & Control & 72 & $2.36 \pm 0.71$ & & & \\
\hline \multirow[t]{2}{*}{ Observe } & $\mathrm{EBT}$ & 57 & $2.48 \pm 0.66$ & 0.21 & 127 & $\mathrm{~ns}$ \\
\hline & Control & 72 & $2.45 \pm 0.59$ & & & \\
\hline \multirow[t]{2}{*}{ Non-judge } & $\mathrm{EBT}$ & 57 & $2.71 \pm 0.61$ & -0.53 & 127 & ns \\
\hline & Control & 72 & $2.76 \pm 0.63$ & & & \\
\hline \multirow[t]{2}{*}{ Non-react } & EBT & 57 & $2.64 \pm 0.58$ & 0.05 & 128 & ns \\
\hline & Control & 73 & $2.63 \pm 0.60$ & & & \\
\hline \multirow[t]{2}{*}{ Describe } & EBT & 57 & $2.87 \pm 0.67$ & 0.70 & 128 & $\mathrm{~ns}$ \\
\hline & Control & 73 & $2.79 \pm 0.68$ & & & \\
\hline
\end{tabular}

Act Aware = Acting with awareness, Observe = Observing, Non-judge $=$ Non-judging of inner experience, Non-react $=$ Non-reactivity of inner experience, Describe = Describing

Table 3. Correlations between mindfulness, mental health and psychological well-being at T1 ( $\mathrm{n}=130)$

\begin{tabular}{|c|c|c|c|c|c|c|}
\hline & CAMS - R & Act Aware & Observe & Non - judge & Non - react & Describe \\
\hline BSI (GSI) & $-0.51^{* *}$ & $-0.52^{* *}$ & 0.07 & $-0.46^{* *}$ & $-0.42^{* *}$ & $-0.34^{* *}$ \\
\hline Depression & $-0.46^{* *}$ & $-0.44 * *$ & -0.11 & $-0.32^{* *}$ & $-0.36^{* *}$ & $-0.27 * *$ \\
\hline Anxiety & $-0.38 * *$ & $-0.41 * *$ & 0.01 & $-0.26^{* *}$ & $-0.36^{* *}$ & $-0.19 *$ \\
\hline Somatisation & $-0.35^{* *}$ & $-0.31^{* *}$ & 0.07 & $-0.21^{*}$ & $-0.23^{* *}$ & -0.02 \\
\hline QoL - NRS & $0.25^{* *}$ & $0.31^{* *}$ & $0.18^{*}$ & 0.16 & $0.28^{* *}$ & $<0.01$ \\
\hline WHOQOL - Bref & $0.60 * *$ & $0.57 * *$ & 0.16 & $0.29 * *$ & $0.41^{* *}$ & $0.30 * *$ \\
\hline SWLS & $0.52^{* *}$ & $0.42^{* *}$ & $0.15^{*}$ & $0.25^{* *}$ & $0.33^{* *}$ & $0.29 * *$ \\
\hline SMiLE & $0.29 * *$ & 0.08 & 0.01 & 0.05 & $0.25^{* *}$ & $0.23^{*}$ \\
\hline
\end{tabular}

Annotations: $* p<0.05, * * p<0.01$. Partial correlations adjusted for age and gender.

Act Aware = Acting with awareness, Observe = Observing, Non-judge = Non-judging of inner experience, Non-react $=$ Non-reactivity of inner experience, Describe = Describing

correlations for the subgroup of bereaved relatives $(n=93)$ were found.

As expected, there was no difference in mindfulness between the intervention and the control group (T1, Table 2). However, mindfulness was a predictor of adaptation and well-being in all relatives (Table 4).

The effects ( $B$-values) in Table 4 show that, e.g., psychological distress (BSI-GSI, range 21-80) at T2 is $4.16 \mathrm{~T}$-points lower, if mindfulness at $\mathrm{T} 1$ is one point (range, 1-4) higher. Similarly, QoL-NRS at T3 is 1.12 (of 10) units higher, if mindfulness at T1 is one point (range, 1-4) higher.

\section{Is the Treatment Effect Mediated By Mindfulness?}

A significant, long-term increase of mindfulness (CAMS-R, adjusted for age, gender, relationship to the patient, time since death, and use of other support) in EBT participants (T1: $2.6 \pm 0.5, \mathrm{~T} 4: 2.8 \pm$ 0.5 ) in comparison to controls (T1: $2.7 \pm 0.4, \mathrm{~T} 4$ :
$2.7 \pm 0.5)$ was found $(\mathrm{T} 1 / \mathrm{T} 4, \mathrm{~B}=-0.19(-0.34$ to $-0.03), p=0.02$ ). A tendency was found in the T1/ T2-comparision ( $p=0.07$ ), no effect in T1/T3. Being another prerequisite for mediation, the effect of the mediator on the outcomes was tested. Regarding T1/T4, a significant effect of Delta mindfulness has been found for all outcome parameters except SMiLE ( $\Delta$ mindfulness, all $p \leq 0.01$, Table 5). If $\Delta$ mindfulness is added into the model for analyzing the impact of the intervention (intervention $+\Delta$ mindfulness), the effects of EBT on depression, QoL-NRS and (by trend) SWLS are diminished which is indicative of a mediation effect.

\section{Impact of Formal and Informal Mindfulness}

Group participants were asked how many times per week they had practiced mindfulness for at least 5 minutes. At T2, participants reported to practice formal mindfulness $3.4 \pm 3.8$ times/week and informal mindfulness $5.7 \pm 9.2$ times/week. There was a significant decline of formal mindfulness practice from 
Table 4. Dispositional mindfulness (T1) as a predictor of adaptation and well-being (T2, T3, and T4)

\begin{tabular}{|c|c|c|c|c|c|c|c|}
\hline \multirow[b]{2}{*}{ Outcome } & \multirow[b]{2}{*}{$n$} & \multirow{2}{*}{$\begin{array}{l}\mathrm{M} \pm \mathrm{SD} \\
\text { Pre (T1) }\end{array}$} & \multirow{2}{*}{$\begin{array}{c}\mathrm{M} \pm \mathrm{SD} \\
\text { Post (T2) }\end{array}$} & \multirow[b]{2}{*}{ B } & \multicolumn{2}{|c|}{ CI (B) } & \multirow[b]{2}{*}{$p$} \\
\hline & & & & & Low & High & \\
\hline BSI (GSI) & 124 & $65.7 \pm 10.7$ & $63.0 \pm 11.7$ & -4.16 & -7.61 & -0.71 & $0.02 *$ \\
\hline QoL-NRS & 123 & $4.0 \pm 1.9$ & $5.2 \pm 2.1$ & 0.71 & -0.04 & 1.47 & 0.06 \\
\hline WHOQOL-Bref & 124 & $62.5 \pm 11.9$ & $65.7 \pm 11.7$ & 1.75 & -1.92 & 5.42 & 0.35 \\
\hline SWLS & 124 & $3.8 \pm 1.2$ & $4.1 \pm 1.2$ & .10 & -0.29 & 0.50 & 0.61 \\
\hline \multirow[t]{2}{*}{ SMiLE } & 111 & $67.6 \pm 18.0$ & $70.3 \pm 17.9$ & 5.75 & -1.26 & 12.76 & 0.11 \\
\hline & & Pre (T1) & Follow-up (T3) & & & & \\
\hline BSI (GSI) & 123 & $65.7 \pm 10.8$ & $62.9 \pm 11.2$ & -5.25 & -9.12 & -1.35 & $0.01 * *$ \\
\hline QoL-NRS & 121 & $4.1 \pm 1.9$ & $5.4 \pm 2.0$ & 1.12 & 0.31 & 1.93 & $0.01 * *$ \\
\hline WHOQOL-Bref & 123 & $62.6 \pm 11.9$ & $66.5 \pm 13.4$ & -0.82 & -6.18 & 4.55 & 0.76 \\
\hline SWLS & 123 & $3.8 \pm 1.2$ & $4.1 \pm 1.3$ & 0.38 & -0.09 & 0.84 & 0.11 \\
\hline \multirow[t]{2}{*}{ SMiLE } & 105 & $68.1 \pm 17.5$ & $69.8 \pm 20.1$ & 10.40 & 0.58 & 20.22 & $\mathbf{0 . 0 4} *$ \\
\hline & & Pre (T1) & Follow-up (T4) & & & & \\
\hline BSI (GSI) & 121 & $65.7 \pm 10.8$ & $60.0 \pm 11.2$ & -2.19 & -6.69 & 2.32 & 0.34 \\
\hline QoL-NRS & 118 & $4.1 \pm 1.2$ & $6.1 \pm 2.1$ & 0.62 & -0.26 & 1.49 & 0.16 \\
\hline WHOQOL-Bref & 121 & $62.6 \pm 12.0$ & $69.4 \pm 12.4$ & -0.05 & -5.23 & 5.16 & 0.99 \\
\hline SWLS & 121 & $3.8 \pm 1.2$ & $4.3 \pm 1.2$ & 0.22 & $-0,25$ & 0.69 & 0.35 \\
\hline SMiLE & 109 & $67.2 \pm 17.9$ & $71.8 \pm 17.4$ & 11.42 & 4.68 & 18.16 & $<0.01 * *$ \\
\hline
\end{tabular}

Annotations: $* p<0.05 ; * p<0.01, \mathrm{~B}=$ regression coefficient, $\mathrm{CI}(\mathrm{B})=$ confidence interval for $\mathrm{B}$. Adjusted for participation in the intervention (yes/no), $\mathrm{T} 1$ values of the outcomes, age, gender, relation to the patient, time since death and use of other support.

T2 to T3 $(2.0 \pm 2.8 ; t=3.7, p<0.01)$ and from T2 to $\mathrm{T} 4(1.0 \pm 1.6 ; t=4.2, p<0.01, n=49)$ but not in informal practice from T2 to T3 $(4.8 \pm 9.0)$ or to $\mathrm{T} 4$ $(5.6 \pm 10.5, \mathrm{~ns}, n=45)$.

In the intervention group, the quartile of participants who practiced mindfulness most frequently (formal: $\geq 5$ times/week, informal: $\geq 7$ times/week) were compared to the low practitioners (Table 6). Frequent formal (but not informal) practice had a significant impact on change of mindfulness, frequent informal (but not formal) practice was followed by an increase in QoL and life satisfaction; MiL was positively and significantly affected both by formal and informal practice.

\section{DISCUSSION}

Mindfulness in informal caregivers of $\mathrm{PC}$ patients was significantly correlated with higher QoL, life satisfaction, the experience of meaning, and lower psychological distress. This parallels findings from other studies reporting correlations with increased well-being and decreased neuroticism and maladaptive coping (Brown \& Ryan, 2003; Feldman et al., 2007).

Regarding the facets of mindfulness, a negative correlation between psychological distress and "Describing/labeling with words," "Acting with awareness," "Non-reactivity to inner experience," and
"Non-judging of experience" was found. These attitudes may help relatives to cope with their experiences. No correlations were found with "Observing": this might be explained by the assumption that observation of internal experiences alone is not adaptive without the accepting attitude cultivated in meditation (Baer et al., 2004; 2006).

Mindfulness has both been described as state and trait. With regard to trait, dispositional mindfulness (T1) was a significant predictor of adjustment for all relatives in both groups. The effect was most significant at the 3 -months follow-up (T1/T3).

Regarding changes of mindfulness (as a state) following the EBT intervention, small but significant effects were found. There are two possible explanations why state mindfulness did not show a larger increase: First, the CAMS-R might not be sufficiently sensitive to change (Brown \& Ryan, 2003; Chiesa \& Malinowski, 2011). Multimodal methods might be needed, e.g., real-time sampling assisted by handheld computers or detailed practice logbooks. However, during intense caregiving and in acute bereavement, these methods might be ethically questionable (Baer, 2003). Second, to achieve an increase in mindfulness, more extensive trainings might be necessary (Orzech et al., 2009). MBSR recommends 45-60 min/day over 8 weeks. 
Table 5. Mediation of long-term (T1-T4) intervention effect by mindfulness $(\mathrm{N}=118)$

\begin{tabular}{|c|c|c|c|c|c|}
\hline & \multirow[b]{2}{*}{ Effect of ... } & \multirow[b]{2}{*}{ B } & \multicolumn{2}{|c|}{ CI } & \multirow[b]{2}{*}{$p$} \\
\hline & & & Low & High & \\
\hline BSI (GSI) & $\begin{array}{l}\text { Intervention } \\
\Delta \text { Mindfulness } \\
\text { Intervention }+\Delta \text { Mindfulness }\end{array}$ & $\begin{array}{r}1.84 \\
-7.84 \\
.24\end{array}$ & $\begin{array}{r}-1.34 \\
-\mathbf{1 1 . 2 9} \\
-2.90 \\
\end{array}$ & $\begin{array}{r}5.01 \\
-\mathbf{4 . 3 9} \\
3.37 \\
\end{array}$ & $\begin{aligned} & 0.29 \\
&<\mathbf{0 . 0 1} * * \\
& 0.88\end{aligned}$ \\
\hline Somatisation & $\begin{array}{l}\text { Intervention } \\
\Delta \text { Mindfulness } \\
\text { Intervention }+\Delta \text { Mindfulness }\end{array}$ & $\begin{array}{l}-0.54 \\
-\mathbf{6 . 4 6} \\
-2.14\end{array}$ & $\begin{array}{r}-4.05 \\
-\mathbf{1 0 . 4 4} \\
-5.79 \\
\end{array}$ & $\begin{array}{r}2.97 \\
-2.47 \\
1.50\end{array}$ & $\begin{array}{c}0.76 \\
<\mathbf{0 . 0 1} * * \\
0.25\end{array}$ \\
\hline Depression & $\begin{array}{l}\text { Intervention } \\
\Delta \text { Mindfulness } \\
\text { Intervention }+\Delta \text { Mindfulness }\end{array}$ & $\begin{array}{r}3.27 \\
-7.24 \\
1.57\end{array}$ & $\begin{array}{r}\mathbf{0 . 1 5} \\
-\mathbf{1 0 . 6 0} \\
-1.51 \\
\end{array}$ & $\begin{array}{r}\mathbf{6 . 3 9} \\
-\mathbf{3 . 8 8} \\
4.64 \\
\end{array}$ & $\begin{array}{c}\mathbf{0 . 0 4}^{*} \\
<\mathbf{0 . 0 1} * * \\
0.32\end{array}$ \\
\hline Anxiety & $\begin{array}{l}\text { Intervention } \\
\Delta \text { Mindfulness } \\
\text { Intervention }+\Delta \text { Mindfulness }\end{array}$ & $\begin{array}{r}1.44 \\
-\mathbf{5 . 3 9} \\
-0.45 \\
\end{array}$ & $\begin{array}{l}-2.26 \\
-\mathbf{9 . 4 6} \\
-4.19\end{array}$ & $\begin{array}{r}5.13 \\
-\mathbf{1 . 3 1} \\
3.29 \\
\end{array}$ & $\begin{array}{l}0.44 \\
\mathbf{0 . 0 1} * * \\
0.81 \\
\end{array}$ \\
\hline QOL-NRS & $\begin{array}{l}\text { Intervention } \\
\Delta \text { Mindfulness } \\
\text { Intervention }+\Delta \text { Mindfulness }\end{array}$ & $\begin{array}{r}-1.18 \\
1.18 \\
-0.75 \\
\end{array}$ & $\begin{array}{r}-1.90 \\
0.40 \\
-1.47 \\
\end{array}$ & $\begin{array}{r}-0.45 \\
1.96 \\
-0.02 \\
\end{array}$ & $\begin{array}{c}<0.01 * * \\
<0.01 * * \\
\mathbf{0 . 0 4}^{*} \\
\end{array}$ \\
\hline WHOQOL-Bref & $\begin{array}{l}\text { Intervention } \\
\Delta \text { Mindfulness } \\
\text { Intervention }+\Delta \text { Mindfulness }\end{array}$ & $\begin{array}{r}-3.60 \\
\mathbf{1 0 . 7 1} \\
-0.71 \\
\end{array}$ & $\begin{array}{r}-7.32 \\
\mathbf{7 . 0 2} \\
-4.02 \\
\end{array}$ & $\begin{array}{r}0.11 \\
14.39 \\
2.60 \\
\end{array}$ & $\begin{array}{rl} & 0.06 \\
<\mathbf{0 . 0 1} & * * \\
& 0.67 \\
\end{array}$ \\
\hline SWLS & $\begin{array}{l}\text { Intervention } \\
\Delta \text { Mindfulness } \\
\text { Intervention }+\Delta \text { Mindfulness }\end{array}$ & $\begin{array}{r}-0.31 \\
\mathbf{0 . 5 0} \\
-0.13 \\
\end{array}$ & $\begin{array}{r}-0.68 \\
\mathbf{0 . 1 0} \\
-0.48 \\
\end{array}$ & $\begin{array}{l}0.06 \\
\mathbf{0 . 9 0} \\
0.23\end{array}$ & $\begin{array}{l}0.09 \\
\mathbf{0 . 0 1} * * \\
0.47 \\
\end{array}$ \\
\hline SMiLE & $\begin{array}{l}\text { Intervention } \\
\Delta \text { Mindfulness } \\
\text { Intervention }+\Delta \text { Mindfulness }\end{array}$ & $\begin{array}{l}0.54 \\
4.41 \\
1.33\end{array}$ & $\begin{array}{l}-5.15 \\
-2.27 \\
-4.62\end{array}$ & $\begin{array}{r}6.22 \\
11.09 \\
7.27\end{array}$ & $\begin{array}{l}0.85 \\
0.19 \\
0.66\end{array}$ \\
\hline
\end{tabular}

Annotations: $* p<0.05, * * p<0.01, \mathrm{~B}=$ regression coefficient, $\mathrm{CI}=$ confidence interval for $\mathrm{B}, \Delta \mathrm{Mindfulness}=\mathrm{CAMS}-\mathrm{R}$ (T4) - CAMS-R (T1). Adjusted for T1 values of the outcomes, age, gender, relation to the patient, time since death and use of other support

Long-term effects of the EBT intervention on depression and QoL appeared to be partly mediated by mindfulness. Although this interaction has to be interpreted cautiously, other studies report similar results (Nyklicek \& Kuijpers, 2008). Group participants evaluated mindfulness as highly positive and transferred both the concept and the practice into their daily life, as has been shown in qualitative interviews (Kögler et al., submitted). Mindfulness seems to be well accepted by relatives during caregiving (Waelde et al., 2004) but establishing regular practice might be difficult in this situation (Oken et al., 2010).

Participants who indicated the highest levels of formal practice had a stronger increase in mindfulness and meaning in life; those with the highest levels of informal practice showed stronger improvements in QoL, life satisfaction, and meaning in life. Formal practice may enhance the ability to focus on the present moment, as measured by the CAMS-R, while doing daily activities with full awareness might positively impact on QoL and life satisfaction (Shapiro et al., 2003).

There are some limitations of our study. The sample was heterogeneous and consisted of bereaved and caregiving relatives in varying relationships to the patient with partners being predominant. All subjects agreed to take part in a randomized controlled trial evaluating a group intervention. These issues may affect the generalizability of the results. However, we wanted to conduct a study that is close to clinical practice and therefore strived to introduce an intervention for informal caregivers at the transition from caring to grieving.

To summarize, the concept of mindfulness was well accepted by relatives of PC patients, both active caregivers as well as bereaved ones. Further research on underlying mechanisms is needed, concerning the format, intensity and type of practice which are most effective in improving well-being und reduce psychological distress. Mindfulness training may be a promising concept for psychosocial support in palliative care. 
Table 6. Impact of mindfulness practice

\begin{tabular}{|c|c|c|c|c|c|c|c|c|}
\hline & & & \multirow{2}{*}{$\mathrm{M} \underset{\mathrm{T} 1}{ \pm \mathrm{SD}}$} & \multirow{2}{*}{$\frac{\mathrm{M}}{\underset{\mathrm{T}}{ \pm} 2}$} & \multirow[b]{2}{*}{ B } & \multicolumn{2}{|c|}{$\mathrm{CI}(\mathrm{B})$} & \multirow[b]{2}{*}{$p$} \\
\hline & & & & & & Low & High & \\
\hline CAMS-R & $\begin{array}{l}\mathbf{F P} \geq \mathbf{5} \\
\mathbf{F P}<\mathbf{5} \\
\mathrm{IP} \geq 7 \\
\mathrm{IP}<7\end{array}$ & $\begin{array}{l}18 \\
48 \\
17 \\
45\end{array}$ & $\begin{array}{l}\mathbf{2 . 7} \pm \mathbf{0 . 5} \\
\mathbf{2 . 6} \pm \mathbf{0 . 5} \\
2.8 \pm 0.5 \\
2.5 \pm 0.5\end{array}$ & $\begin{array}{l}\mathbf{2 . 9} \pm \mathbf{0 . 5} \\
\mathbf{2 . 7} \pm \mathbf{0 . 5} \\
2.8 \pm 0.6 \\
2.7 \pm 0.5\end{array}$ & $\begin{array}{r}-0.27 \\
.08\end{array}$ & $\begin{array}{l}-\mathbf{0 . 0 5} \\
-0.17\end{array}$ & $\begin{array}{r}-\mathbf{0 . 0 1} \\
0.34 \\
\end{array}$ & $\begin{array}{l}\mathbf{0 . 0 2} * \\
0.52 \\
\end{array}$ \\
\hline BSI (GSI) & $\begin{array}{l}\mathrm{FP} \geq 5 \\
\mathrm{FP}<5 \\
\mathrm{IP} \geq 7 \\
\mathrm{IP}<7\end{array}$ & $\begin{array}{l}18 \\
48 \\
17 \\
45\end{array}$ & $\begin{array}{l}63.4 \pm 11.0 \\
67.1 \pm 11.3 \\
64.7 \pm 11.6 \\
66.6 \pm 11.2\end{array}$ & $\begin{array}{l}59.2 \pm 11.6 \\
63.6 \pm 12.7 \\
60.9 \pm 13.5 \\
62.3 \pm 12.0\end{array}$ & $\begin{array}{r}2.50 \\
.76 \\
\end{array}$ & $\begin{array}{l}-1.92 \\
-4.05 \\
\end{array}$ & $\begin{array}{l}6.91 \\
5.57 \\
\end{array}$ & $\begin{array}{l}0.26 \\
0.75 \\
\end{array}$ \\
\hline QoL-NRS & $\begin{array}{l}\mathrm{FP} \geq 5 \\
\mathrm{FP}<5 \\
\mathrm{IP} \geq 7 \\
\mathrm{IP}<7\end{array}$ & $\begin{array}{l}18 \\
48 \\
17 \\
\mathbf{4 5}\end{array}$ & $\begin{array}{l}4.1 \pm 2.1 \\
3.8 \pm 1.7 \\
\mathbf{3 . 4} \pm \mathbf{1 . 9} \\
\mathbf{3 . 9} \pm \mathbf{1 . 7}\end{array}$ & $\begin{array}{l}6.1 \pm 2.0 \\
5.5 \pm 2.0 \\
\mathbf{6 . 0} \pm \mathbf{2 . 1} \\
\mathbf{5 . 4} \pm \mathbf{2 . 0}\end{array}$ & $\begin{array}{l}-0.57 \\
-\mathbf{1 . 0 8}\end{array}$ & $\begin{array}{l}-1.58 \\
-\mathbf{2 . 1 3}\end{array}$ & $\begin{array}{r}0.44 \\
-\mathbf{0 . 0 3} \\
\end{array}$ & $\begin{array}{l}0.26 \\
\mathbf{0 . 0 5}^{*} \\
\end{array}$ \\
\hline WHOQOL-Bref & $\begin{array}{l}\mathrm{FP} \geq 5 \\
\mathrm{FP}<5 \\
\mathrm{IP} \geq 7 \\
\mathrm{IP}<7\end{array}$ & $\begin{array}{l}18 \\
48 \\
17 \\
45\end{array}$ & $\begin{array}{l}62.0 \pm 13.0 \\
62.4 \pm 10.9 \\
64.9 \pm 12.9 \\
60.9 \pm 11.0\end{array}$ & $\begin{array}{l}68.6 \pm 12.7 \\
66.5 \pm 11.8 \\
71.0 \pm 13.5 \\
65.6 \pm 11.1\end{array}$ & $\begin{array}{l}-2.92 \\
-1.23\end{array}$ & $\begin{array}{l}-6.75 \\
-5.40 \\
\end{array}$ & $\begin{array}{l}0.91 \\
2.80 \\
\end{array}$ & $\begin{array}{l}0.13 \\
0.53 \\
\end{array}$ \\
\hline SWLS & $\begin{array}{l}\mathrm{FP} \geq 5 \\
\mathrm{FP}<5 \\
\mathrm{IP} \geq 7 \\
\mathrm{IP}<7\end{array}$ & $\begin{array}{l}18 \\
48 \\
\mathbf{1 7} \\
\mathbf{4 5}\end{array}$ & $\begin{array}{l}3.7 \pm 1.4 \\
3.7 \pm 1.1 \\
\mathbf{3 . 8} \pm \mathbf{1 . 3} \\
\mathbf{3 . 7} \pm \mathbf{1 . 2}\end{array}$ & $\begin{array}{l}4.3 \pm 1.3 \\
4.2 \pm 1.1 \\
\mathbf{4 . 6} \pm \mathbf{1 . 2} \\
\mathbf{4 . 1} \pm \mathbf{1 . 1}\end{array}$ & $\begin{array}{l}-0.25 \\
-\mathbf{0 . 5 1}\end{array}$ & $\begin{array}{l}-0.73 \\
-\mathbf{1 . 0 1}\end{array}$ & $\begin{array}{r}0.23 \\
-\mathbf{0 . 0 2} \\
\end{array}$ & $\begin{array}{l}0.30 \\
\mathbf{0 . 0 4} *\end{array}$ \\
\hline SMiLE & $\begin{array}{l}\text { FP } \geq 5 \\
\text { FP }<5 \\
\text { IP } \geq 7 \\
\text { IP }<7\end{array}$ & $\begin{array}{l}17 \\
45 \\
17 \\
45\end{array}$ & $\begin{array}{l}63.0 \pm 16.3 \\
71.4 \pm 15.7 \\
68.3 \pm 14.9 \\
68.7 \pm 17.4\end{array}$ & $\begin{array}{l}77.0 \pm 12.2 \\
71.8 \pm 17.3 \\
78.9 \pm \mathbf{9 . 7} \\
71.3 \pm 16.7\end{array}$ & $\begin{array}{l}-9.12 \\
-7.13\end{array}$ & $\begin{array}{l}-17.36 \\
-14.36\end{array}$ & $\begin{array}{r}-0.89 \\
0.10\end{array}$ & $\begin{array}{l}0.03^{*} \\
0.05^{*}\end{array}$ \\
\hline
\end{tabular}

Annotations: $* p<0.05, * * p<0.01, \mathrm{FP}=$ Formal practice IP $=$ Informal practice; $\mathrm{B}=$ regression coefficient, $\mathrm{CI}=$ confidence interval for B, Adjusted for T1 values of the outcomes, age, gender, relation to the patient, time since death and use of other support.

\section{ACKNOWLEDGMENT}

This research was supported by Deutsche Krebshilfe e.V. (No. 107433). The authors declare no conflict of interest.

\section{REFERENCES}

Angermeyer, M.C., Kilian, R. \& Matschinger, H. (2000). WHOQOL-100 und WHOQOL-BREF (WHOQOL-100 and WHOQOL-BREF). Handbuch für die deutschsprachige Version der WHO Instrumente zur Erfassung von Lebensqualität (Handbook for the German language version of the WHO Quality of Life Instruments). Göttingen: Hogrefe.

Baer, R. (2003). Mindfulness training as a clinical intervention: a conceptual and empirical review. Clinical Psychology: Science and Practice, 10, 125-143.

Baer, R.-A., Smith, G.-T. \& Allen, K.-B. (2004). Assessment of mindfulness by self-report: The Kentucky inventory of mindfulness skills. Assessment, 11, 191-206.

Baer, R.-A., Smith, G.-T., Hopkins, J., et al. (2006). Using self-report assessment methods to explore facets of mindfulness. Assessment, 13, 27-45.

Brown, K.-W. \& Ryan, R.-M. (2003). The benefits of being present: Mindfulness and its role in psychological well- being. Journal of Personality and Social Psychology, $84,822-848$.

Carmody, J. \& Baer, R.A. (2009). How long does a mindfulness-based stress reduction program need to be? A review of class contact hours and effect sizes for psychological distress. Journal of clinical psychology, 65, 627-638.

Chentsova-Dutton, Y., Shucter, S., Hutchin, S., et al. (2002). Depression and grief reactions in hospice caregivers: From pre-death to 1 year afterwards. Journal of Affective Disorders, 69, 53-60.

Chiesa, A. \& Malinowski, P. (2011). Mindfulness-based approaches: Are they all the same? Journal of Clinical Psychology, 67, 404-424.

Diener, E., Emmons, R.A., Larsen, R.J., et al. (1985). The satisfaction with life scale. Journal of Personality Assessment, 49, 71-75.

Fegg, M., Brandstätter, M., Kögler, M., et al. (2013). Existential behavioural therapy for informal caregivers of palliative patients: A randomised controlled trial. Psycho-Oncology doi:10.1002/pon.3260.

Fegg, M., Kramer, M., L'hoste, S., et al. (2008). The schedule for meaning in life evaluation (SMiLE): Validation of a new instrument for meaning-in-life research. Journal of Pain and Symptom Management, 4, 356-363.

Feldman, G., Hayes, A., Kumar, S., et al. (2007). Mindfulness and emotion regulation: The development and 
initial validation of the cognitive and affective mindfulness scale-revised (CAMS-R). Journal of Psychopathology and Behavioral Assessment, 29, 177-190.

Franke, G. (2000). Brief Symptom Inventory von Derogatis (BSI). Kurzform der SCL-90-R (Brief symptom Inventory (BSI) by Derogatis. Short form of the SCL-90-R). Göttingen: Hogrefe Testzentrale.

Grossman, P., Niemann, L., Schmidt, S., et al. (2004). Mindfulness-based stress reduction and health benefits: A metaanalysis. Journal of Psychosomatic Research, 57, 35-43.

Hayes, S.C., Luoma, J., Bond, F., et al. (2006). Acceptance and commitment therapy: Model, processes and outcomes. Behaviour Research and Therapy, 44, 1-25.

Kabat-Zinn, J. (2003). Mindfulness-based interventions in context: Past, present, and future. Clinical Psychology: Science and Practice, 10, 144-156.

Kang, H.-Y. \& Yoo, Y.-S. (2007). Effects of a bereavement intervention program in middle-aged widows in Korea. Archives of Psychiatric Nursing, 21, 132-140.

Kissane, D., McKenzie, M., McKenzie, D., et al. (2003). Psychosocial morbidity associated with patterns of family functioning in palliative care: Baseline data from the Family focused grief therapy controlled trial. Palliative Medicine, 17, 527-537.

Kögler, M., Brandl, J., Brandstätter, M., et al. (submitted). "Determinants of the effect of Existential Behavioural Therapy for bereaved partners: A qualitative study. Journal of Palliative Medicine.

Kumar, S.M. (2005). Grieving Mindfully: A Compassionate and Spiritual Guide to Coping with Loss, Oakland: New Harbinger Publications.

Nyklicek, I. \& Kuijpers, K. (2008). Effects of mindfulnessbased stress reduction intervention on psychological well-being and quality of life: Is increased mindfulness indeed the mechanism? Annals of Behavioral Medicine, $35,331-340$.

Nyklicek, I., van Son, J. \& Pouwer, F. (2010). Two recently published meta-analyses on the effectiveness of mind- fulness-based interventions: What should the reader make of it? Journal of Psychosomatic Research, 69, $613-614$

Oken, B., Fonareva, I., Haas, M., et al. (2010). Pilot controlled trial of mindfulness meditation and education for dementia caregivers. Journal of Alternative \& Complementary Medicine, 16, 1031-1038.

Orzech, K.M., Shapiro, S.L., Brown, K.W., et al. (2009). Intensive mindfulness training-related changes in cognitive and emotional experience. The Journal of Positive Psychology, 4, 212-222.

Robins, C.J. \& Chapman, A.L. (2004). Dialectical behavior therapy: Current status, recent developments, and future directions. Journal of Personality Disorders, 18, $73-89$.

Shapiro, S., Bootzin, R., Figueredo, A., et al. (2003). The efficacy of mindfulness-based stress reduction in the treatment of sleep disturbance in women with breast cancer: An exploratory study. Journal of Psychosomatic Research, 54, 85-91.

Shapiro, S.L., Carlson, L.E., Astin, J.A., et al. (2006). Mechanisms of mindfulness. Journal of Clinical Psychology, $62,373-386$.

Teasdale, J.D., Segal, Z.V., Williams, J.M.G., et al. (2000). Prevention of relapse/recurrence in major depression by mindfulness-based cognitive therapy. Journal of Consulting and Clinical Psychology, 68, 615-623.

Toneatto, T. \& Nguyen, L. (2007). Does mindfulness meditation improve anxiety and mood symptoms? A review of the controlled research. Canadian Journal of Psychiatry, 52, 260-266.

Vickers, A. \& Altman, D. (2001). Analysing controlled trials with baseline and follow up measurements. BMJ, 323, 1123-1124.

Waelde, L.C., Thompson, L. \& Gallagher-Thompson, D. (2004). A pilot study of a yoga and meditation intervention for dementia caregiver stress. Journal of Clinical Psychology, 60, 677-687. 